Article

\title{
Facile Oil Removal from Water-in-Oil Stable Emulsions Using PU Foams
}

\author{
Suset Barroso-Solares $1,2, * \mathbb{(})$, Javier Pinto ${ }^{1,2}\left(\mathbb{D}\right.$, Despina Fragouli ${ }^{1}(\mathbb{C})$ and \\ Athanassia Athanassiou 1,*(D) \\ 1 Smart Materials, Istituto Italiano di Tecnologia, via Morego 30, 16163 Genova, Italy; jpinto@fmc.uva.es (J.P.); \\ despina.fragouli@iit.it (D.F.) \\ 2 Cellular Materials (CellMat) Research Group, Condensed Matter Physics Department, University of \\ Valladolid, Paseo de Belen 7, 47011 Valladolid, Spain \\ * Correspondence: sbarroso@fmc.uva.es (S.B.-S.); athanassia.athanassiou@iit.it (A.A.)
}

Received: 1 November 2018; Accepted: 26 November 2018; Published: 27 November 2018

\begin{abstract}
Superhydrophobic and oleophilic polyurethane foams were obtained by spray-coating their surfaces with solutions of thermoplastic polyurethane and hydrophobic silicon oxide nanoparticles. The developed functionalized foams were exploited as reusable oil absorbents from stable water-in-oil emulsions. These foams were able to remove oil efficiently from a wide range of emulsions with oil contents from 10 to $80 \mathrm{v} . \%$, stabilized using Span80. The modified foams could reach oil absorption capacities up to $29 \mathrm{~g} / \mathrm{g}$, becoming a suitable candidate for water-in-oil stable emulsions separation.
\end{abstract}

Keywords: wetting properties; absorption; oil-water emulsions; polymer foams

\section{Introduction}

Polymer foams are biphasic materials composed of a polymer matrix and a gaseous phase. However, this apparently simple definition hinders a vast complexity, in which the characteristics of each phase, the geometrical configuration of the phases (in terms of sizes or distribution), and the interactions between them play a decisive role in their physical properties [1]. The understanding of some of the underlying relationships of this complexity, achieved after decades of research, has proved polymer foams as highly versatile materials which are currently widely employed in transportation, thermal and acoustic insulation, packaging, commodity, or construction [1]. Nevertheless, further comprehension and exploitation of the polymer foams features can still expand their potential applications. On the one hand, recent works on the development of nanocellular polymers [2] and nanocomposite foams [3] enhanced the understanding of these materials and suggested new potential applications (e.g., transparent foams, high-performance thermal insulators, electromagnetic shielding, energy storage) [2-5]. On the other hand, a new generation of functional polymer foams have been proposed in the last years for several water remediation applications, a research field that has become a global priority (e.g., contaminated drinking water is estimated to cause half a million deaths each year) [6]. Polymer foams have been successfully proposed to remove heavy metal ions from water [7,8], as well as to develop bactericide water filters by introducing silver or copper nanoparticles [9-12] and have attracted a large interest and shown a great performance in water-oil separation applications [13].

Water-oil separation has become a worldwide need in numerous industrial production areas, as huge amounts of oily wastewaters are produced from diverse industrial process, presenting severe environmental and health risks [14]. Efficient separation approaches have been proposed by the development of simultaneously superhydrophobic and superoleophilic polymeric foams. These materials can exclusively absorb oil and repel water, presenting also high oil absorption 
capacities [13,15-19]. The majority of the proposed approaches have been focused on the absorption of free oil from water, simulating oil spills [13,15-19]. A large number of polymer foams have been employed as an in situ oil spills remediation approach, using them mainly as oil absorbents. These materials can be placed in the surface of the polluted water, where they absorb only the oil, and then recovered [13]. Although different polymer matrices have been tested with this aim, polyurethane and melamine foams have shown the best performances [13], as the very high porosity achievable by both kinds of foams led to very high oil absorption capacities [13,20]. Moreover, other parameters, such as the cell size and the cell connectivity, also play a significant role in the water-oil separation process [20]; while the improvement of the separation efficiency of these materials has been widely attempted by functionalization procedures [13].

However, oil spills and industrial oily wastewaters commonly do not present only free oil in the surface of the water but also emulsified oil (i.e., small oil droplets dispersed in water, or small water droplets dispersed in oil) [14]. This circumstance has been usually not taken into account by previous works using polymer foams in the remediation of oil spills, and the results of the free oil removal performance of these materials cannot be extrapolated to actual scenarios with emulsified oil. It is well-known that the separation of emulsions is more challenging than the separation of free oil from water, especially in the presence of surfactants that make the emulsions very stable [21,22]. Up to the knowledge of the authors, only a few recent works have studied the suitability of such polymeric foams for the separation of non-stabilized emulsions [23,24]. In particular, Wang and Zheng [23] have modified polyurethane (PU) foams with stearic acid by dip-coating in order to fabricate superhydrophobic/superoleophilic foams exhibiting excellent durability, high free oil absorption capacities up to $41.6 \mathrm{~g} / \mathrm{g}$, and also an acceptable surfactant-free oil-in-water emulsions separation efficiency (transparency of filtrate: $>80 \%$ ). Also, Wang et al. [24] proposed carbon nanotube/poly(dimethylsiloxane)-coated PU foams for the continuous separation of surfactant-free water-in-oil emulsions with high efficiency (recovered oil purity: >99.97 wt.\%), demonstrating that, in non-stabilized emulsions, properly functionalized polymeric foams can be efficiently employed on gravity-driven separation processes $[25,26]$. However, the separation of stable water-oil emulsions employing porous absorbents has been scarcely reported in the literature. On the one hand, a few works employing other porous materials (e.g., fibrous mats, porous membranes) as oil absorbents report successful results when employed in stable water-oil emulsions [27-31]. On the other hand, just Li et al. [22] have proposed the use of polymer foams for the separation of surfactant-stabilized oil-in-water emulsions. They followed a multiple-step procedure to modify attapulgite particles, providing them a superhydrophobic/superhydrophilic behavior, and then transfer the particles to polyurethane foams. These functionalized polyurethane foams were tested in oil-in-water emulsions with a $50 \%$ volume percentage of oil and stabilized using Tween 80 . The separation procedure was carried out by compressing and agitating the PU foams in the emulsions, reaching separation efficiency about $99 \%$ in that particular conditions.

It has been widely proved that polymer foams are suitable candidates for the separation of free oil and non-stabilized emulsions. However, there are just a few evidences about their use on stable emulsions, which are very common in actual remediation scenarios (e.g., some components of crude oils are known to stabilize emulsions in oil spills). Thus, it still should be proved if polymer foams, preferably obtained by facile functionalization procedures, could be employed in the separation of stable emulsions with a wide range of oil contents. Moreover, the incorporation of fillers or coatings to the polymer foams could also modify their mechanical properties [32,33], being necessary to ensure that the functionalization procedure does not damage the mechanical performance of the foams.

Herein, we proposed the use of functionalized polymer foams for the separation of stable water-in-oil emulsions presenting a wide range of oil contents. We obtained simultaneously superhydrophobic and oleophilic polyurethane foams via a facile single-step route, by spray-coating their surfaces with a homogeneous solution of thermoplastic polyurethane (TPU) and hydrophobic silicon oxide nanoparticles (SNPs) in chloroform. The developed functional foams presented high 
oil separation efficiency in stable water-in-oil emulsions, while their mechanical properties were not affected by the functionalization procedure. Moreover, these foams could be reused for at least 50 cycles of oil absorption/oil recovery achieving a stable performance, proving that the developed systems can be used as efficient absorbents in wastewater and oil-polluted water treatment even if stable emulsions are present.

\section{Materials and Methods}

\subsection{Materials}

Polyurethane foams with the same porosity $(0.975)$ and different pore sizes $(\Phi)$ (see Table 1$)$, provided by Recticel Flexible Foams Inc (Wetteren, Belgium), were used in this study. Thermoplastic polyurethane (TPU, Elastollan ${ }^{\circledR} 1185 \mathrm{~A}, \mathrm{BASF}$ ) was employed as coating of the foams' surfaces. Hydrophobic silicon oxide fumed nanoparticles (SNPs, AEROSIL ${ }^{\circledR} \mathrm{R} 812, \rho \approx 2 \mathrm{~g} / \mathrm{cm}^{3}$ at $20{ }^{\circ} \mathrm{C}$, Evonik Industries AG) with sizes between 5 and $40 \mathrm{~nm}$ were employed as nanofillers in the TPU coating. Mineral oil ( $\rho=0.84 \mathrm{~g} / \mathrm{cm}^{3}$ a $25{ }^{\circ} \mathrm{C}$, Sigma-Aldrich) and distilled water were mixed to obtain emulsions, using Span 80 (Sorbitan monooleate, non-ionic, viscosity $1200-2000 \mathrm{mPa} \cdot \mathrm{s}$ at $20^{\circ} \mathrm{C}$, Hydrophile-Lipophile Balance (HLB) value $4.3 \pm 1.0, \rho=0.986 \mathrm{~g} / \mathrm{cm}^{3}$ at $25^{\circ} \mathrm{C}$, Sigma-Aldrich) as water-in-oil emulsion stabilizer. Chloroform $\left(\mathrm{CHCl}_{3}\right.$, Purity, Gas chromatography $(\mathrm{GC})>99.8 \%, \rho=$ $1.48 \mathrm{~g} / \mathrm{cm}^{3}$ at $20{ }^{\circ} \mathrm{C}$, Sigma-Aldrich) was used as received as common solvent for the TPU and SNPs, whereas ethanol (Ethyl alcohol-d6, Purity (GC) $>99.5 \%, \rho=0.892 \mathrm{~g} / \mathrm{cm}^{3}$ at $25^{\circ} \mathrm{C}$, Sigma-Aldrich) was employed for the rinsing of the treated foams.

Table 1. Polyurethane (PU) pristine foams' properties: pore size, apparent water contact angle (AWCA), and water and oil absorption capacities.

\begin{tabular}{ccccc}
\hline Foam & Pore Size $(\mu \mathrm{m})$ & AWCA $\left(^{\circ}\right)$ & $C_{\text {water }}(\mathrm{g} / \mathrm{g})$ & $\boldsymbol{C}_{\text {oil }}(\mathrm{g} / \mathrm{g})$ \\
\hline PU-1 & 1741 & $98.4 \pm 11.0$ & $28.94 \pm 0.14$ & $23.25 \pm 0.10$ \\
PU-2 & 817 & $122.8 \pm 7.6$ & $31.01 \pm 2.95$ & $29.62 \pm 0.24$ \\
PU-3 & 435 & $133.3 \pm 4.4$ & $15.64 \pm 3.18$ & $30.50 \pm 0.01$ \\
\hline
\end{tabular}

\subsection{Fabrication of Treated PU Foams (PUT)}

The external surfaces of PU foam samples cut in cubes of $1 \mathrm{~cm}^{3}$ were coated using a spray-coating set-up [34]. Each one of the six facets of the foam samples was coated with a $3 \mathrm{~mL}$ solution of $2.5 \mathrm{mg} / \mathrm{mL}$ hydrophobic silicon oxide fumed nanoparticles (SNPs) and $7.5 \mathrm{mg} / \mathrm{mL}$ thermoplastic polyurethane in chloroform. The distance between the nozzle head and the samples were modified obtaining treated PU foams (PUT) with different surface roughness after drying at room temperature (RT). A distance of $20 \mathrm{~cm}$ was identified as optimal to carry out the procedure, providing a proper roughness increase and coating stability (see Supplementary Materials, Figure S1). All samples were allowed to dry at room temperature, and then washed by immersion in ethanol for 30 min under sonication operating at $59 \mathrm{kHz}$ (Labsonic LBS2, FALC Instruments). Then, the samples were rinsed with water and mechanically squeezed, up to $90 \%$ of deformation, with the aim to remove the remaining water and any unattached coating (see Supplementary Materials, Figure S1).

\subsection{Preparation of Emulsions}

Stable emulsions were prepared following the procedure described in a previous work, where the stability of these emulsions was also studied [28]. First, Span80 was dissolved into the oil phase ( $0.5 \mathrm{wt} . \%)$ by shaking for $24 \mathrm{~h}$. Then, the aqueous phase was added to the mixture to form the Span80-stabilized emulsions and dispersed using a high-intensity ultrasonication tip (VCX 750, Vibra cell, SONICS) at $40 \%$ amplitude for $15 \mathrm{~s}$ at room temperature. The concentrations of the emulsions are expressed using the volume percentage of the oil (v.\%). Six-mL water-in-oil emulsions were prepared for the absorption tests with oil contents of 10,30,50, and $80 \mathrm{v} . \%$, which correspond 
to oil amounts of $0.504,1.512,2.520$, and $4.032 \mathrm{~g}$, respectively). All these emulsions are rather stable, presenting no changes after $30 \mathrm{~min}$ as proved elsewhere [28].

\subsection{Characterization}

The weight increase (wt.\%) of the foams due to the functionalization procedure was determined by weighing the samples before $\left(w_{P U}\right)$ and after the treatment $\left(w_{P U T}\right)$ (Equation (1)).

$$
w t . \%=\frac{\left(w_{P U T}-w_{P U}\right)}{w_{P U}} \cdot 100
$$

The foams' morphology was examined by scanning electron microscopy (SEM, JEOL Model JSM-6490) (Boston, MA, USA), being the samples previously coated with gold. Moreover, a KSVCAM200 (Kruss, Germany) contact angle goniometer was used to determine the apparent contact angle of the foams for water (AWCA) and oil (AOCA), averaging five measurements for each kind of sample, using 5- $\mu$ l drops at RT. As the measurement of the contact angle in polymer foams can be affected by the pore size the obtained values are defined as "apparent" contact angles (see Supplementary Materials, Figure S4) [20].

Oil and water absorption capacity (respectively $C_{\text {oil }}$ and $C_{\text {water }}$ ), as well as the simultaneous oil and water uptakes from emulsions (respectively $w_{\text {oil }}$ and $w_{\text {water }}$ ), of both pristine and treated foams were determined with samples of $1 \mathrm{~cm}^{3}$ in contact with $6 \mathrm{~mL}$ of the tested liquid for $15 \mathrm{~min}$.

The water and oil absorption capacity $\left(C_{\text {water }}\right.$ and $\left.C_{\text {oil }}\right)$ were obtained after immersing the foams in water or oil, while the simultaneous water and oil uptake $\left(w_{\text {water }}\right.$ and $\left.w_{\text {oil }}\right)$ were obtained after immersing the foams in water-in-oil emulsions [28]. All these values are expressed as the mass of the absorbed liquid divided by the mass of the absorbent $(\mathrm{g} / \mathrm{g})$. Due to the buoyancy of the samples, and to increase the contact between the foams and the emulsions, the foams were forced and kept below the surface of the water during the absorption experiments (See Supplementary Material, Figure S5).

On the one hand, $C_{\text {water }}$ and $C_{\text {oil }}$ were calculated using Equations (2) and (3), respectively.

$$
\begin{gathered}
C_{\text {water }}[g / g]=\frac{w_{\text {abswater }}-w_{\text {foam }},}{w_{\text {foam }}}, \\
C_{\text {oil }}[g / g]=\frac{w_{\text {absoil }}-w_{\text {foam }}}{w_{\text {foam }}},
\end{gathered}
$$

where $w_{\text {foam }}$ is the initial weight of the foams, and $w_{\text {abswater }}$ and $w_{\text {foam }}$ are the weights of the foams after being in contact with the water or the oil, respectively.

On the other hand, the simultaneous water $\left(w_{\text {water }}\right)$ and oil $\left(w_{\text {oil }}\right)$ uptakes from emulsions were calculated using Equations (4) and (5), respectively.

$$
\begin{gathered}
w_{\text {water }}[g / g]=\frac{A b s_{1}-A b s_{2}}{w_{\text {foam }}}, \\
w_{\text {oil }}[g / g]=\frac{A b s_{2}-w_{\text {foam }}}{w_{\text {foam }}},
\end{gathered}
$$

where the foams' weight were measured before $\left(w_{\text {foam }}\right)$ and immediately after being extracted from the emulsions $\left(A b s_{1}\right)$. Then, the samples were stored in an oven at $50{ }^{\circ} \mathrm{C}$ for one week, with the aim to ensure the complete water evaporation from the samples and weighted again $\left(A b s_{2}\right)$. Following this procedure, it was possible to identify separately the amount of absorbed oil $\left(w_{\text {oil }}\right)$ and water $\left(w_{\text {water }}\right)$.

The optimal contact time of $15 \mathrm{~min}$ between the foams and the emulsions was established by analyzing the evolution of the water and oil uptakes with the contact time. It was found that the best oil absorption selectivity was achieved after $15 \mathrm{~min}$ (i.e., simultaneous higher oil uptake and lower water uptake). Shorter contact times led to incomplete foam saturation, while longer times 
decreased the oil absorption selectivity (i.e., the oil uptake decreased, and the water uptake increased). Accordingly, this contact time was employed for all the oil absorption tests from emulsions, as well as for the reference oil and water absorption capacity tests.

The absorption selectivity of the foams towards the oil (\%) was determined by analyzing the composition of the liquid absorbed by the foams from the emulsions. Accordingly, the absorption selectivity $(\%)$ was defined as the percentage of oil uptake $\left(\mathrm{w}_{\mathrm{oil}}\right)$ present on the liquid absorbed by the foam $\left(w_{\text {oil }}+w_{\text {water }}\right)$, as shown in Equation (6).

$$
\text { Absorption selectivity } \%=\frac{w_{\text {oil }}}{w_{\text {oil }}+w_{\text {water }}} \cdot 100,
$$

Finally, it was studied the potential reusability of the PUT foams. Their oil absorption efficiency was analyzed for 50 absorption cycles for the emulsions presenting the higher and lower oil contents and 5 absorption cycles for the intermediate emulsions, being the samples rinsed with ethanol and dried subsequently to each absorption cycle.

Additionally, the functionalization stability was studied for 50 washing/drying cycles with ethanol by Fourier-transform infrared (FTIR) spectroscopy using a Bruker Tensor 27 spectrometer equipped with a MKII Golden-Gate diamond attenuated total reflectance (ATR) unit at room temperature in the range of $600-4000 \mathrm{~cm}^{-1}$. Also, the mechanical properties of the pristine (PU) and treated foams (PUT) were evaluated using samples with dimensions of $1 \times 1 \times 1 \mathrm{~cm}^{3}$ through cyclic compressive tests at RT using a PerkinElmer DMA7 dynamic mechanical analyzer (DMA) with a parallel-plate system (top plate of $12 \mathrm{~mm}$ in diameter). Samples were tested in force control at $20^{\circ} \mathrm{C}$, applying an increasing force $(500 \mathrm{mN} / \mathrm{min})$ up to $2 \mathrm{~N}$ and then allowing the recovery of the sample without load for two minutes. Test were performed for a duration of 33 cycles.

\section{Results and Discussion}

First, it was identified the optimal porous structure among the different PU foams (see Table 1) to be favorable towards oil absorption and unfavorable towards water absorption. Thus, the absorption of the pristine foams was separately tested in water or oil. It was found that the highest $C_{\text {oil }}(\sim 30.5 \mathrm{~g} / \mathrm{g})$ and the lowest $C_{\text {water }}(\sim 15.6 \mathrm{~g} / \mathrm{g})$ were obtained for the PU foams with the smallest average pore size $(435 \mu \mathrm{m}$, see Table 1$)$, in good agreement with previous works [13]. Additionally, all the foams presented a superoleophilic behavior $\left(\mathrm{AOCA} \approx 0^{\circ}\right.$ ), whereas an increase of the AWCA was measured by decreasing the pore size (Table 1 ), raising from $98^{\circ}$ to $133^{\circ}$ when the pore size of the PU foams was modified from $1741 \mu \mathrm{m}$ to $435 \mu \mathrm{m}$.

This trend was further verified by testing the pristine foams with stable water-in-oil emulsions presenting oil contents ranging from 10 to $80 \mathrm{v} . \%$. It was found that for all the PU foam under study the evolution of the simultaneous water $\left(w_{\text {water }}\right)$ and oil uptakes $\left(w_{\text {oil }}\right)$ was clearly related to the composition of the water-in-oil emulsion employed. After being in contact with emulsions with low oil contents, the pristine PU foams absorbed high amounts of water and small amounts of oil; while high oil contents led into higher oil than water absorption. Regarding the influence of the pore size, the foams with the smallest pore size obtained the lowest $w_{\text {water }}$ simultaneously with the greatest $w_{\text {oil }}$, regardless of the emulsion tested (Figure 1a,b), confirming that the reduction of the pore size was also improving the performance of the foams when tested in stable emulsions. However, even for the smallest pore size, the selectivity towards oil absorption was not optimal (i.e., a significant amount of water was also absorbed, particularly from emulsions with low oil content (10 v.\%)) (Figure 1c). For this reason, it was necessary to functionalize the surface of the foams aiming to improve their selectivity. 


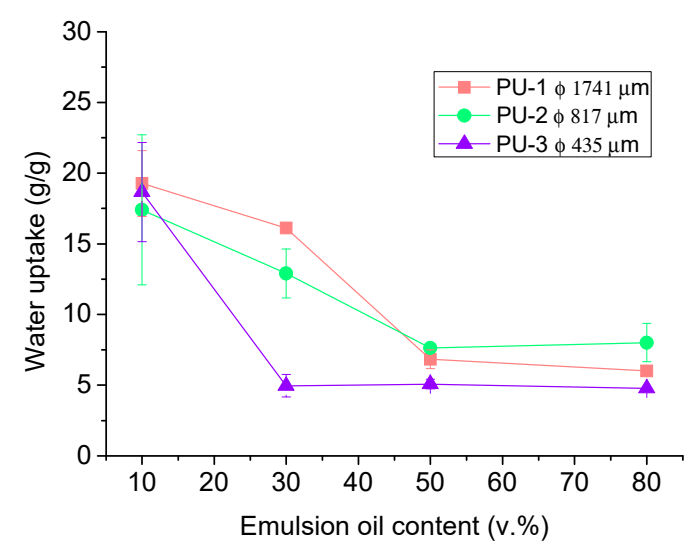

(a)

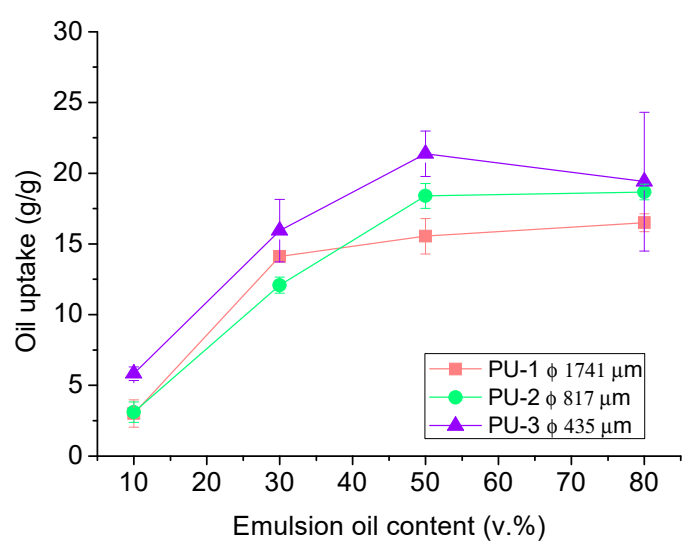

(b)

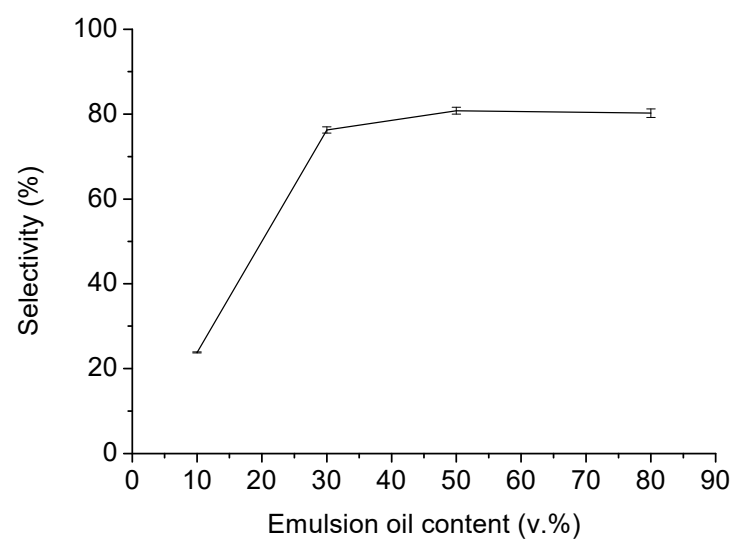

(c)

Figure 1. Simultaneous $(\mathbf{a})$ water $\left(w_{\text {water }}\right)$ and $(\mathbf{b})$ oil uptake $\left(w_{\text {oil }}\right)$ from stable water-in-oil emulsions using pristine PU foams with different pore sizes. Oil absorption selectivity (c) of PU-3 ( $\Phi=435 \mu \mathrm{m})$ from stable water-in-oil emulsions.

Therefore, samples of the PU-3 foam, with the smallest pore size, were functionalized by spray-coating with TPU and SNPs starting from chloroform solutions (see Materials and Methods). This treatment did not modify the porosity of the foams or the pore size (Figure 2), but it slightly increased the mass of the foams by $4.54 \pm 1.11 \mathrm{wt} . \%$ and the roughness of the pores' walls and the external surfaces of the foams. These modifications were stable even after five washing cycles of the foams with ethanol (Figure 2).

The modification of the external surfaces of the foams increased the AWCA by $15^{\circ}$ (from $133.3 \pm 4.4^{\circ}$ (PU-3) to $149.9 \pm 1.8^{\circ}$ (PUT)) while maintaining the superoleophilicity. The applied coating was stable and provided a constant AWCA after five washing cycles with ethanol. This change in the wettability of the modified foams was responsible for the drastic reduction of their water absorption, achieving almost negligible $C_{\text {water }}(0.20 \mathrm{~g} / \mathrm{g})$ compared to the untreated foams $(15.64 \mathrm{~g} / \mathrm{g})$ when the samples were tested in water. At the same time, the new $C_{\text {oil }}(29.08 \mathrm{~g} / \mathrm{g})$ remained almost unaltered compared to the untreated foams $(30.50 \mathrm{~g} / \mathrm{g})$ after being placed on the surface of the oil, being the slight decrease related to the total weight increase of the foams after the treatment (see Supporting Information, Figure S3).

An improved and stable performance, compared to the untreated PU foams, was also found when the PUTs were used in stabilized water-in-oil emulsions. This improved behavior was confirmed for up to 50 immersion-ethanol washing cycles (Figure 3). It was found that the $w_{\text {water }}$ decreased for all the emulsions, reaching values below $2.5 \mathrm{~g} / \mathrm{g}$, independently of the emulsion (Figure 3a), well below the values obtained without treatment (from 5.0 to $20.0 \mathrm{~g} / \mathrm{g}$, see Figure 1a). Furthermore, the $w_{\text {oil }}$ 
increased for all the emulsions, reaching values near or over $20.0 \mathrm{~g} / \mathrm{g}$ for emulsions with oil contents over $30 \mathrm{v} . \%$ (Figure $3 \mathrm{~b}$ ). It should be noticed that the amount of oil present in the emulsions with 10 wt.\% oil (0.504 g) was significantly lower than the amount of oil that the foams employed in the tests could absorb (about $0.8-1.0 \mathrm{~g}$ ), and therefore, the maximum $w_{\text {oil }}$ that could be reached in this case was just $\sim 15 \mathrm{~g} / \mathrm{g}$.
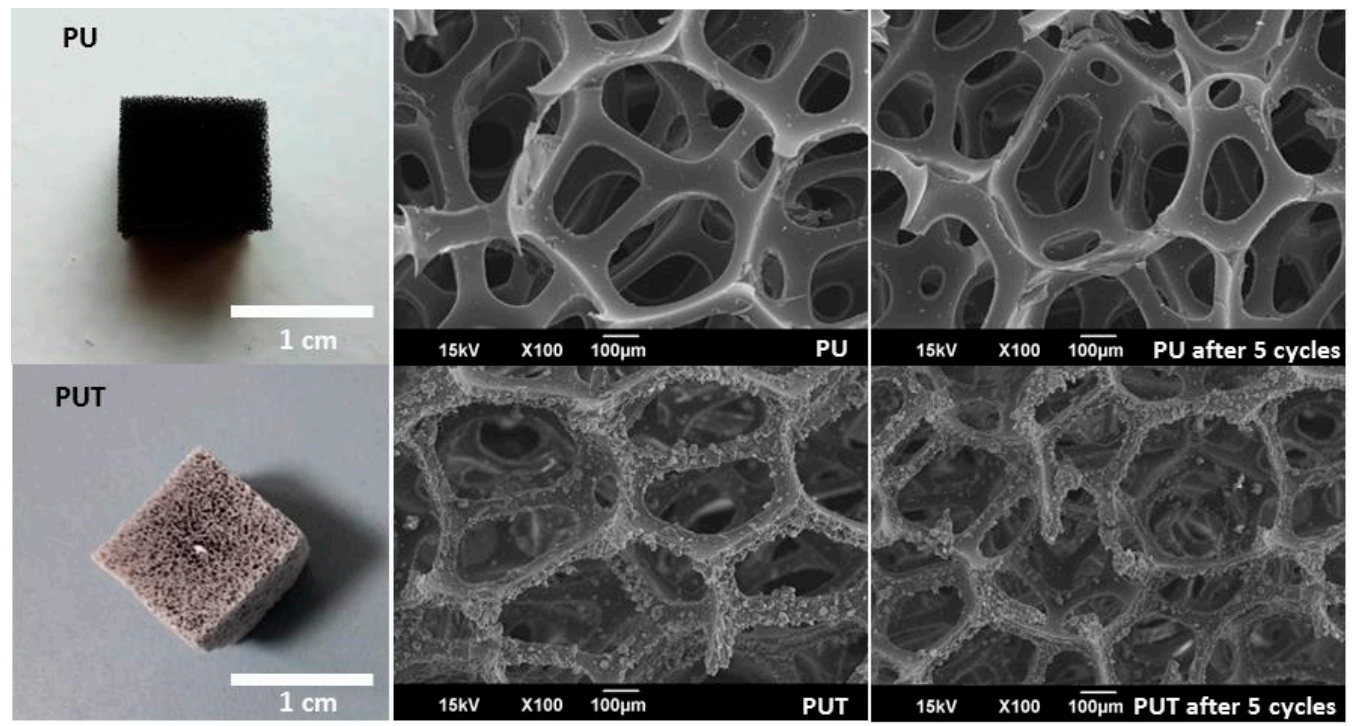

Figure 2. Photographs (left) of PU (up) and treated PU foams (PUT) (down) foams, and SEM micrographs of their porous structure before (middle) and after five washing cycles with ethanol (right).

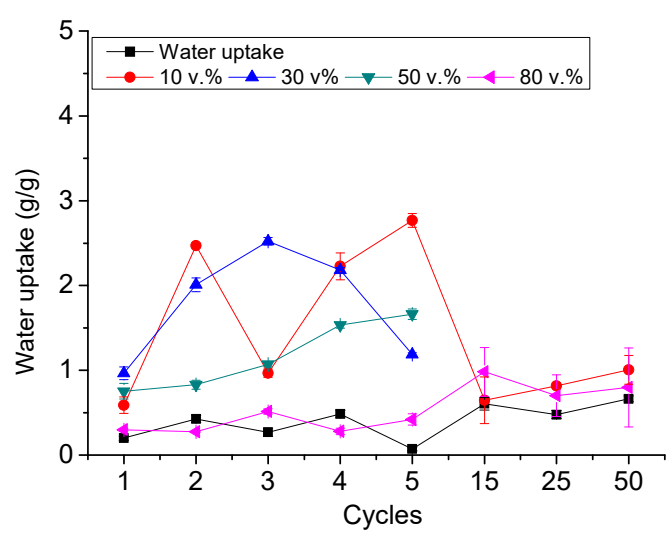

(a)

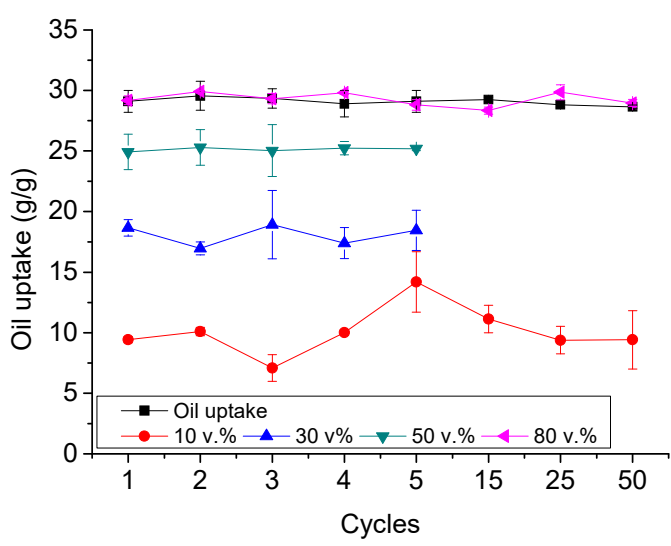

(b)

Figure 3. Simultaneous (a) water ( $\mathrm{w}_{\text {water }}$ ) and (b) oil uptakes $\left(\mathrm{w}_{\text {oil }}\right)$ of PUT foams from stable water-in-oil emulsions up to 50 absorption/washing cycles.

Also, the analysis of the absorption selectivity of the foams towards the oil provides clear evidence of the beneficies of the functionalization procedure. The pristine PU-3 foams (see Figure 1c) did not present a proper absorption selectivity, being their selectivity at low oil contests about only $20 \%$, reaching maximum selectivity values of about $75-80 \%$ at medium-high oil contents. On the contrary, PUT foams presented a clear selective absorption behavior independently of the oil content (see Figure 4). It was found that for the first use, the selectivity towards oil absorption of the PUT was higher than $95 \%$, independently of the starting emulsion (even in emulsions with only $10 \mathrm{v} . \%$ of oil) (Figure 4). In the following cycles, only a slight decrease in the selectivity was found, eventually obtaining a stable selectivity up to 50 cycles over $80 \%$ for emulsions with 10 and $30 \mathrm{v} . \%$ oil content, and over $90 \%$ for emulsions with 50 and $80 \mathrm{v} . \%$ oil content. 


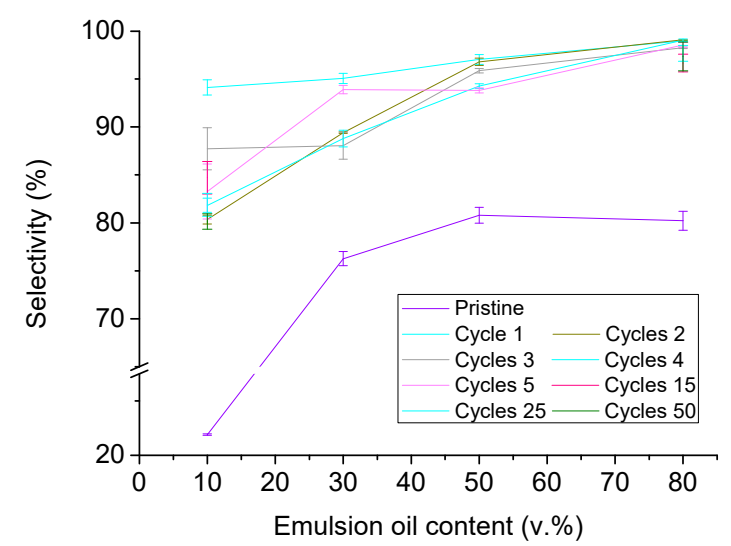

Figure 4. Oil absorption selectivity of PUT foams from stable water-in-oil emulsions up to 50 absorption/washing cycles.

Further work was carried out in order to characterize the stability of the treatment of the PUT foams. First, an FITR study was carried out with PUT samples subjected up to 50 washing cycles with ethanol. It was analyzed the evolution of the TPU presence on the surface of the PUT foams as an indicator of the presence of the treatment on these surfaces. The ratio between the PUT foams peaks respectively at about $1078 \mathrm{~cm}^{-1}\left(I_{1078}\right.$, contributed by both the PU and TPU, see Figure 5a) and $1124 \mathrm{~cm}^{-1}$ ( $I_{1124}$, contributed mainly by the PU, see Figure $\left.5 \mathrm{a}\right)$, both peaks related to vibrations of $\mathrm{C}-\mathrm{O}-\mathrm{C}$ groups $[35,36]$, was employed with this aim.

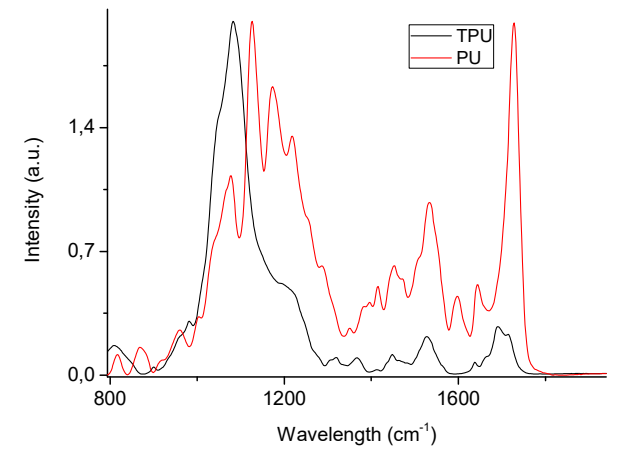

(a)

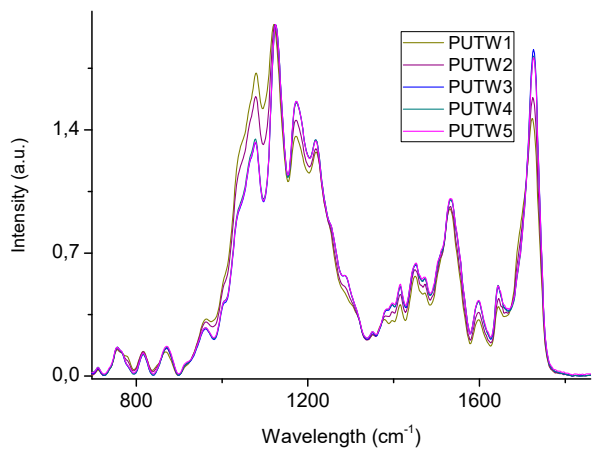

(b)

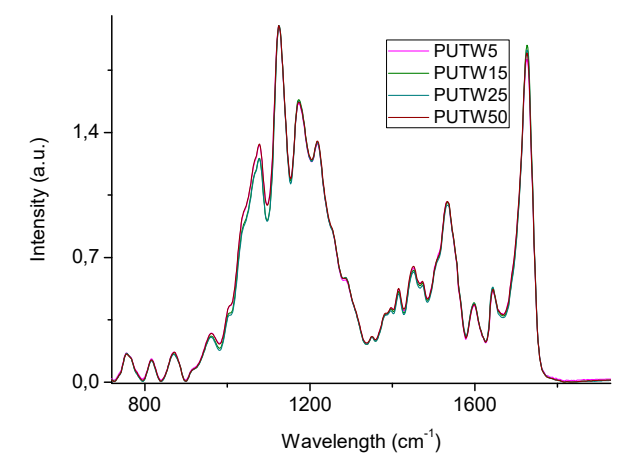

(c)

Figure 5. FTIR spectra of (a) PU foams and thermoplastic polyurethane (TPU), (b) PUT samples after 1 (PUTW1), 2 (PUTW2), 3 (PUTW3), 4 (PUTW4), and 5 (PUTW5) washing cycles), and (c) PUT samples after 5, 15 (PUTW15), 25 (PUTW20), and 50 (PUTW50) washing cycles. Full spectra can be found in the Supplementary Materials (see Figure S7). 
It was found that there was a slight treatment lost from the first to the third washing cycles (Figure $5 b$ ), as the $I_{1078} / I_{1124}$ ratio decreased from 0.86 to 0.66 . This result is in good agreement with the oil absorption selectivity of the samples, which also showed a slight decrease after the first absorption/washing cycles (see Figure 4) but then reached a rather stable performance in the following cycles. Moreover, this study was extended up to 50 washing cycles, finding that the $I_{1078} / I_{1124}$ ratio was rather constant after the first cycles, presenting values between 0.62-0.66. Although this slight loss of the coating presents an effect on the selectivity of the first cycles, it was found to be no significant in terms of the weight of the foam (see Supplementary Materials, Table S1). Moreover, no nanoparticles release was found during these tests (see Supplementary Materials, Table S1). Therefore, it was demonstrated that the functionalization procedure followed to produce the PUT foams was rather stable, at least up to 50 washing cycles.

Finally, as the compression of polymer foams has been proposed in the literature as a suitable procedure to recover the absorbed oil [34], the mechanical behavior of the PU foams before and after the treatment was analyzed. In particular, pristine PU foams, functionalized PUT foams, and functionalized PUT foams after 50 washing cycles were subjected to 33 successive compression cycles (see Materials and Methods). As Figure 6 clearly shows, no clear difference in the stress relaxation due to viscous deformation after 33 compressive deformation cycles was found between any of the studied samples. Therefore, it was proved that neither the treatment procedure, nor the washing procedure modified the mechanical behavior of the employed PU foams, being the obtained PUT foams mechanically and chemically stable.

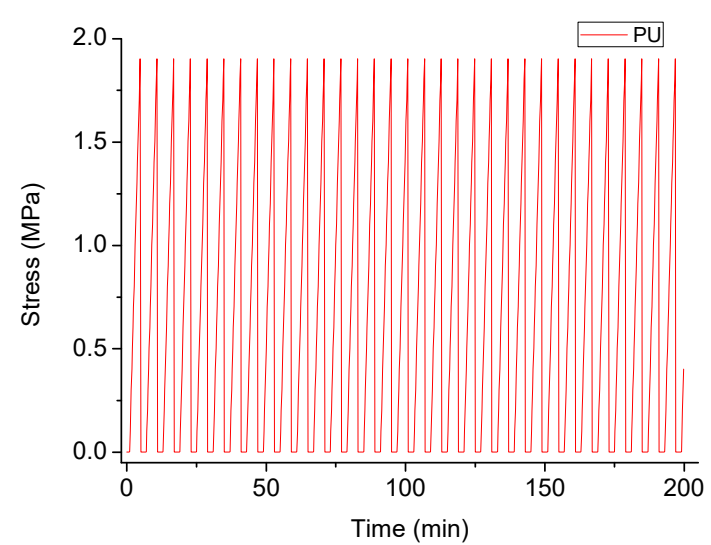

(a)

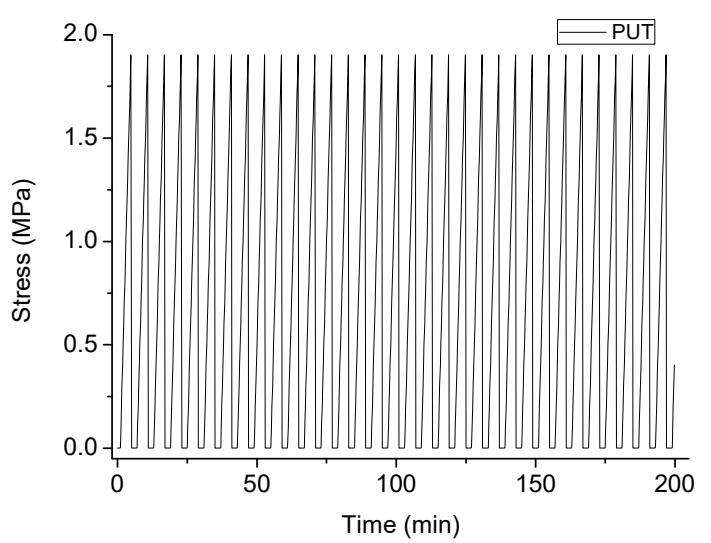

(b)

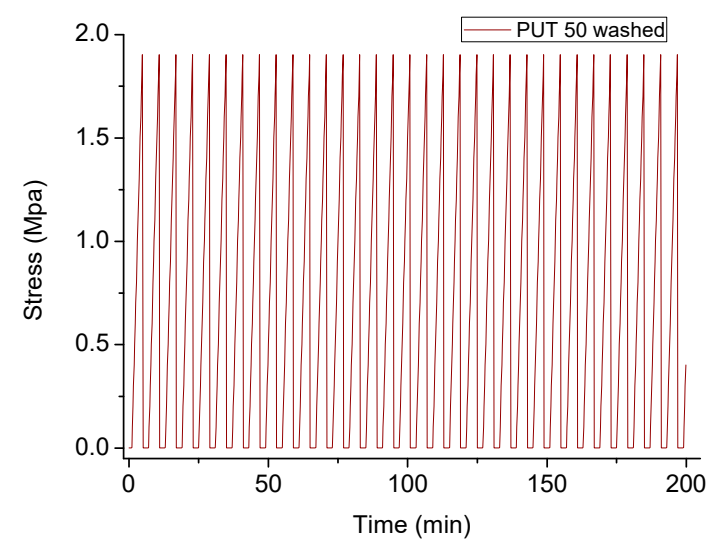

(c)

Figure 6. Stress-time curves for 33 deformation cycles of (a) pristine PU foams, (b) functionalized PUT foams, and (c) functionalized PUT foams after 50 washing cycles. 


\section{Conclusions}

Functionalized PU foams with optimized wetting properties and oil separation efficiency from stable water-in-oil emulsions were obtained by a single-step spray-coating, using silica nanoparticles and thermoplastic polyurethane as a nanocomposite coating. These foams reached a maximum oil absorption capacity of about $30 \mathrm{~g} / \mathrm{g}$, as well as a selectivity above $95 \%$ for stable emulsions with oil contents from 10 to $80 \mathrm{v} . \%$. Also, the stability of the coating and the mechanical properties of the foam, proved to be stable up to 50 washing cycles, allowed the reuse of the treated foams after ethanol washing up to at least 50 absorption cycles without a significant performance loss, making these functional foams efficient oil absorbents for oily wastewaters, including emulsions stabilized by a surfactant.

Supplementary Materials: The following are available online at http:/ / www.mdpi.com/1996-1944/11/12/2382/ s1. Figure S1. Spray-coating set-up. Figure S2 Optical micrographs of PUT obtained by modifying the distance between the nozzle head and the samples. Figure S3. UV-Vis spectra of silica nanoparticles dispersed in ethanol (black), remaining ethanol after being in contact with treated foams not subjected to the initial washing procedure (red), and remaining ethanol after being in contact with treated foams subjected to the initial washing procedure and absorption tests (blue). Figure S4. Water drop placed in a PU pore, where $\theta$ is the real contact angle of water (WCA), and $\gamma$ is the apparent contact angle (APCA) measured by the optical contact angle goniometer (a). Figures (b) and (c) illustrate the influence of the pore size on the apparent contact angle of water drops with the same size. Figure S5. Schematic representation (a) and photograph (b) of the absorption tests set-up. Figure S6. Water and oil absorption capacity using PU and PUT foams. Figure S7. FTIR spectra of PU foams and TPU (a), PUT samples after 1 (PUTW1), 2 (PUTW2), 3(PUTW3), 4 (PUTW4), and 5 (PUTW5) washing cycles (b), and PUT samples after 5 , 15 (PUTW15), 25(PUTW20), and 50 (PUTW50) washing cycles (c). Table S1. Mass Increase of PUT foams obtained using different spray-coating distances and their stability during five consecutive washing cycles. The first one is part of the production route of the treated foams, as described in section 2.2, while the following four cycles are perfomed to study the stability of the treatment once the treated foams has been produced. Table S2. Oil and water absorption capacity of PU and PUT foams.

Author Contributions: Conceptualization, S.B.-S.; Investigation, S.B.-S. and J.P.; Supervision, D.F. and A.A.; Writing—original draft, S.B.-S.; Writing—review \& editing, J.P. and A.A.

Funding: This research received no external funding.

Conflicts of Interest: The authors declare no conflict of interest.

\section{References}

1. Gibson, L.J.; Ashby, M.F. Cellular Solids: Structure and Properties; Cambridge University Press: Cambridge, UK, 1999.

2. Notario, B.; Pinto, J.; Rodriguez-Perez, M.A. Nanoporous polymeric materials: A new class of materials with enhanced properties. Prog. Mater. Sci. 2016, 78-79, 93-139. [CrossRef]

3. Antunes, M.; Velasco, J.I. Multifunctional polymer foams with carbon nanoparticles. Prog. Polym. Sci. 2014, 39, 486-509. [CrossRef]

4. Wang, H.; Li, T.-T.; Wu, L.; Lou, C.-W.; Lin, J.-H. Multifunctional, Polyurethane-Based Foam Composites Reinforced by a Fabric Structure: Preparation, Mechanical, Acoustic, and EMI Shielding Properties. Materials 2018, 11, 2085. [CrossRef] [PubMed]

5. Su, X.; Jia, S.; Lv, G.; Yu, D. A Unique Strategy for Polyethylene Glycol/Hybrid Carbon Foam Phase Change Materials: Morphologies, Thermal Properties, and Energy Storage Behavior. Materials 2018, 11, 2011. [CrossRef] [PubMed]

6. WHO. Drinking-Water. Available online: http://www.who.int/mediacentre/factsheets/fs391/en/ (accessed on 7 February 2018).

7. Chavan, A.A.; Pinto, J.; Liakos, I.; Bayer, I.S.; Lauciello, S.; Athanassiou, A.; Fragouli, D. Spent Coffee Bioelastomeric Composite Foams for the Removal of $\mathrm{Pb}^{2+}$ and $\mathrm{Hg}^{2+}$ from Water. ACS Sustain. Chem. Eng. 2016, 4, 5495-5502. [CrossRef]

8. Chavan, A.A.; Li, H.; Scarpellini, A.; Marras, S.; Manna, L.; Athanassiou, A.; Fragouli, D. Elastomeric nanocomposite foams for the removal of heavy metal ions from water. ACS Appl. Mater. Interfaces 2015, 7, 14778-14784. [CrossRef] [PubMed] 
9. Pinto, J.; Magrì, D.; Valentini, P.; Palazon, F.; Heredia-Guerrero, J.A.; Lauciello, S.; Barroso-Solares, S.; Ceseracciu, L.; Pompa, P.P.; Athanassiou, A.; et al. Antibacterial Melamine Foams Decorated with in Situ Synthesized Silver Nanoparticles. ACS Appl. Mater. Interfaces 2018, 10, 16095-16104. [CrossRef] [PubMed]

10. Phong, N.T.P.; Thanh, N.V.K.; Phuong, P.H. Fabrication of antibacterial water filter by coating silver nanoparticles on flexible polyurethane foams. J. Phys. Conf. Ser. 2009, 187, 12079. [CrossRef]

11. Deng, C.H.; Gong, J.L.; Zhang, P.; Zeng, G.M.; Song, B.; Liu, H.Y. Preparation of melamine sponge decorated with silver nanoparticles-modified graphene for water disinfection. J. Colloid Interface Sci. 2017, 488, $26-38$. [CrossRef] [PubMed]

12. Sportelli, M.C.; Picca, R.A.; Ronco, R.; Bonerba, E.; Tantillo, G.; Pollini, M.; Sannino, A.; Valentini, A.; Cataldi, T.R.I.; Cioffi, N. Investigation of industrial polyurethane foams modified with antimicrobial copper nanoparticles. Materials 2016, 9, 544. [CrossRef] [PubMed]

13. Pinto, J.; Athanassiou, A.; Fragouli, D. Surface modification of polymeric foams for oil spills remediation. J. Environ. Manag. 2018, 206, 872-889. [CrossRef] [PubMed]

14. Adebajo, M.O.; Frost, R.L.; Kloprogge, J.T.; Carmody, O.; Kokot, S. Porous Materials for Oil Spill Cleanup: A Review of Synthesis and Absorbing Properties. J. Porous Mater. 2003, 10, 159-170. [CrossRef]

15. Liu, L.; Lei, J.; Li, L.; Zhang, R.; Mi, N.; Chen, H.; Huang, D.; Li, N. A facile method to fabricate the superhydrophobic magnetic sponge for oil-water separation. Mater. Lett. 2017, 195, 66-70. [CrossRef]

16. Hou, K.; Jin, Y.; Chen, J.; Wen, X.; Xu, S.; Cheng, J.; Pi, P. Fabrication of superhydrophobic melamine sponges by thiol-ene click chemistry for oil removal. Mater. Lett. 2017, 202, 99-102. [CrossRef]

17. Fan, Y.; He, Y.; Luo, P.; Chen, X.; Yu, Z.; Li, M. Facile way in building superhydrophobic zirconium surface for controllable water-oil separation. Mater. Lett. 2017, 188, 115-118. [CrossRef]

18. Calcagnile, P.; Fragouli, D.; Bayer, I.S.; Anyfantis, G.C.; Martiradonna, L.; Cozzoli, P.D.; Cingolani, R.; Athanassiou, A. Magnetically Driven Floating Foams for the Removal of Oil Contaminants from Water. ACS Nano 2012, 6, 5413-5419. [CrossRef] [PubMed]

19. Tan, J.; Li, W.; Ma, C.; Wu, Q.; Xu, Z.; Liu, S. Synthesis of honeycomb-like carbon foam from larch sawdust as efficient absorbents for oil spills cleanup and recovery. Materials 2018, 11, 1106. [CrossRef] [PubMed]

20. Pinto, J.; Athanassiou, A.; Fragouli, D. Effect of the porous structure of polymer foams on the remediation of oil spills. J. Phys. D Appl. Phys. 2016, 49, 145601-145608. [CrossRef]

21. Tao, M.; Xue, L.; Liu, F.; Jiang, L. An intelligent superwetting PVDF membrane showing switchable transport performance for oil/water separation. Adv. Mater. 2014, 26, 2943-2948. [CrossRef] [PubMed]

22. Li, J.; Xu, C.; Zhang, Y.; Wang, R.; Zha, F.; She, H. Robust superhydrophobic attapulgite coated polyurethane sponge for efficient immiscible oil/water mixture and emulsion separation. J. Mater. Chem. A 2016, 4, 15546-15553. [CrossRef]

23. Wang, J.; Zheng, Y. Oil/water mixtures and emulsions separation of stearic acid-functionalized sponge fabricated via a facile one-step coating method. Sep. Purif. Technol. 2017, 181, 183-191. [CrossRef]

24. Wang, C.F.; Lin, S.J. Robust Superhydrophobic/superoleophilic sponge for effective continuous absorption and expulsion of oil pollutants from Water. ACS Appl. Mater. Interfaces 2013, 5, 8861-8864. [CrossRef] [PubMed]

25. Paul, U.; Fragouli, D.; Bayer, I.; Athanassiou, A. Functionalized Cellulose Networks for Efficient Oil Removal from Oil-Water Emulsions. Polymers 2016, 8, 52. [CrossRef]

26. Nikkhah, A.A.; Zilouei, H.; Asadinezhad, A.; Keshavarz, A. Removal of oil from water using polyurethane foam modified with nanoclay. Chem. Eng. J. 2015, 262, 278-285. [CrossRef]

27. Barroso-Solares, S.; Pinto, J.; Nanni, G.; Fragouli, D.; Athanassiou, A. Enhanced oil removal from water in oil stable emulsions using electrospun nanocomposite fiber mats. RSC Adv. 2018, 8, 7641-7650. [CrossRef]

28. Barroso-Solares, S.; Zahedi, M.G.; Pinto, J.; Nanni, G.; Fragouli, D.; Athanassiou, A. Oil removal from water-oil emulsions using magnetic nanocomposite fibrous mats. RSC Adv. 2016, 6, 71100-71107. [CrossRef]

29. Li, X.; Wang, M.; Wang, C.; Cheng, C.; Wang, X. Facile immobilization of Ag nanocluster on nanofibrous membrane for oil/water separation. ACS Appl. Mater. Interfaces 2014, 6, 15272-15282. [CrossRef] [PubMed]

30. Huang, M.; Si, Y.; Tang, X.; Zhu, Z.; Ding, B.; Liu, L.; Zheng, G.; Luo, W.; Yu, J. Gravity driven separation of emulsified oil-water mixtures utilizing in situ polymerized superhydrophobic and superoleophilic nanofibrous membranes. J. Mater. Chem. A 2013, 1, 14071-14074. [CrossRef] 
31. Wang, X.; Xiao, C.; Liu, H.; Huang, Q.; Hao, J.; Fu, H. Poly(vinylidene fluoride-hexafluoropropylene) porous membrane with controllable structure and applications in efficient oil/water separation. Materials 2018, 11, 443. [CrossRef] [PubMed]

32. Pan, Y.; Zhan, J.; Pan, H.; Wang, W.; Tang, G.; Song, L.; Hu, Y. Effect of Fully Biobased Coatings Constructed via Layer-by-Layer Assembly of Chitosan and Lignosulfonate on the Thermal, Flame Retardant, and Mechanical Properties of Flexible Polyurethane Foam. ACS Sustain. Chem. Eng. 2016, 4, 1431-1438. [CrossRef]

33. Linul, E.; Linul, P.; Valean, C.; Marsavina, L.; Silaghi-Perju, D. Manufacturing and Compressive Mechanical Behavior of Reinforced Polyurethane Flexible (PUF) Foams. IOP Conf. Ser. Mater. Sci. Eng. 2018, 416, 012053. [CrossRef]

34. Pinto, J.; Heredia-Guerrero, J.A.; Athanassiou, A.; Fragouli, D. Reusable nanocomposite-coated polyurethane foams for the remediation of oil spills. Int. J. Environ. Sci. Technol. 2017. [CrossRef]

35. Hejna, A.; Kirpluks, M.; Kosmela, P.; Cabulis, U.; Haponiuk, J.; Piszczyk, Ł. The influence of crude glycerol and castor oil-based polyol on the structure and performance of rigid polyurethane-polyisocyanurate foams. Ind. Crops Prod. 2017, 95, 113-125. [CrossRef]

36. Asefnejad, A.; Khorasani, M.T.; Behnamghader, A.; Farsadzadeh, B.; Bonakdar, S. Manufacturing of biodegradable polyurethane scaffolds based on polycaprolactone using a phase separation method: physical properties and in vitro assay. Int. J. Nanomed. 2011, 6, 2375-2384. [CrossRef] [PubMed]

(C) 2018 by the authors. Licensee MDPI, Basel, Switzerland. This article is an open access article distributed under the terms and conditions of the Creative Commons Attribution (CC BY) license (http://creativecommons.org/licenses/by/4.0/). 